\title{
Editorial: Excessive Police Violence as a Public Health Issue
}

\author{
Hannah L. F. Cooper and Mindy Fullilove
}

This special issue of the Journal of Urban Health was organized in response to a series of widely reported deaths and sexual assaults of Black children and adults by the police in the USA. This particular series began with the deaths of Michael Brown in Ferguson MO, Eric Garner in New York City NY, 12-year-old Tamir Rice in Cleveland OH, Sandra Bland in Waller County, TX, and Freddy Gray in Baltimore $\mathrm{MD}$, and the sexual assault of Jannie Ligons and 12 other girls and women in Oklahoma City OK. With rare exception, police officer after police officer has been absolved of wrong-doing. Meanwhile, cities have paid millions of dollars to settle civil claims, thus acknowledging the profound harms that have been done.

In response to these events, a massive protest movement has arisen under the umbrella of "Black Lives Matter." The rallies and marches have forced the issue of unjustified police violence to the fore and consistently kept it in the public eye. At the same time, the growing availability of video cameras and the rapid dissemination of videos online have brought the last moments of these lives and the testimonies of assaulted women into the homes of the nation. It is hard to watch the police gun down an unarmed person without crying out against unfairness.

While police cars are labeled with slogans such as "to serve and protect," this racially biased epidemic of violence has raised the question, "How can we stop this?" That question calls us to study the epidemic, bringing all the weight of public health science to bear on untangling this phenomenon. In truth, however, public health has historically remained largely silent about the consequences of excessive police violence for health and health equity. This silence is striking for many reasons. Violence itself has long been framed as a public health issue, ${ }^{1}$ and achieving health equity has been central to public health's mission for decades. ${ }^{2}$ Additionally, public health's increasing recognition that social policies shape patterns of health and disease $^{3,4}$ has created opportunities to engage with law enforcement policies and practices as social determinants of health. With the exception of research and interventions with active drug users and sex workers, e.g., ${ }^{5-8}$ however, public health has rarely studied or intervened in excessive police violence as a social determinant of health.

In this issue of the journal, a group of researchers has stepped forward to begin to sketch the health consequences of excessive police violence and to explore possible solutions. They point out that we face a problem that is rooted in the use of violence to enforce centuries of oppression against Black adults and children in the USA. At the present time, this violence is an obvious and hurtful part of daily life in poor

Cooper is with the Rollins School of Public Health at Emory University, Atlanta, GA 30322, USA; Fullilove is with the Columbia University Mailman School of Public Health, New York, NY 10032, USA. Correspondence: Hannah L. Cooper, Rollins School of Public Health at Emory University, Atlanta, GA 30322, USA. (E-mail: hcoope3@emory.edu) 
ghettoes. Finally, we learn that efforts to change these patterns have been fiercely resisted and quickly undone.

\section{EXCESSIVE POLICE VIOLENCE UNDERMINES HEALTH}

Several papers reviewed for this special issue examine the health effects of excessive police-related violence using multiple measures of police violence, outcomes, and methods with different populations living in different settings. All converge on the conclusion that living in conditions of excessive police violence adversely affects health. By analyzing data from the New York Police Department (NYPD), Sewell and Jefferson create several measures of stop and frisk (e.g., number of stop and frisks per 100 residents; proportion of stops involving frisking; ethnoracial disparities in stop rates) within New York City (NYC) neighborhoods. They then use multilevel methods to analyze whether and how these neighborhood-level measures are associated with several health outcomes (e.g., high blood pressure, diabetes, self-rated health, recent asthma occurrence), measured at the level of individuals. In $80 \%$ of associations analyzed, they find that residents of neighborhoods with higher rates of stop and frisk were more likely to be in poor health. Gomez employed qualitative methods to explore perceptions of policing, social cohesion, and stress among Black residents of Baltimore neighborhoods with high arrest rates. She finds that participants reported that police were present not to protect residents of predominately Black neighborhoods but to surveil and intimate them, and that the War on Drugs was in truth a War on Black people. Police actions routinely undermined local social cohesion and led to considerable stress.

Markwick and colleagues expand the traditional definition of policing to include private security forces, a vital expansion given increases in the number of security guards and in the size of the terrain they patrol. ${ }^{9}$ In a sample of 30 people who use drugs in Vancouver Canada and who reported a recent encounter with security guards, this qualitative study found that participants experienced pervasive, discriminatory profiling, surveillance, and excessive physical and psychological violence, particularly participants of Aboriginal descent, and that this profiling, surveillance, and violence restricted participants' access to public and private spaces, including pharmacies and hospitals where they received vital health services.

\section{IT IS A RELATIVELY INTRACTABLE PROBLEM}

Several papers in the issue describe efforts to rein in police violence. McGregor uses mixed methods to document the history of efforts to establish a civilian review board in Newark, NJ. Public awareness of excess police force extends back centuries, but became a central issue in 1967, when the beating of the cab driver John Smith triggered the Newark uprising. Though decades of advocacy had failed to create a civilian police review board, a confluence of factors-federal oversight, the Black Lives Matter Movement, and the election of Ras Baraka as Mayor-created a turning point. McGregor's study ends with that advance so its efficacy is not examined. Green and Hutto Sr. investigate community efforts to stop police homicides in Prince George's County, MD, a county that went from majority White to majority Black in the last 30 years. Their historical review, which utilizes a "classic Marxist" perspective that racist police violence helps the bourgeoisie maintain their hegemony, finds that egregious police practices were tamed by 
federal intervention, but appear to be in resurgence now that that oversight has ended. Concern that good interventions do not last is echoed in Evans and Saligari's paper, which described efforts to stop police homicides of people with mental illness. An intervention had the desired effect, but, Evans and Saligari found, the effect waned after the intervention ended.

\section{IT GROWS FROM AND CONTRIBUTES TO IRRATIONAL NARRATIVES ABOUT DANGER}

Gabler and Wright explore how communal narratives of police brutality perpetuate racialization and future brutality. Analyzing Darren Wilson's testimony about his killing of Michael Brown, Gabler and Wright find that Wilson portrays Brown as a demonically aggressive, nonhuman monster, a perspective echoed by mainstream media, which characterized Brown as a "thug" and a "gangster." Characterizations of Black men as monstrously aggressive and inhuman resonate historically, and support future state violence against this group.

\section{BETTER THEORIES AND DATA CAN HELP}

Richardson, St. Vil and Cooper open their paper by quoting trauma surgeon Dr. Roy Smith, who said, "I've never had someone say they were shot by the police who wasn't and I've been doing this for 25 years." They examine the imprecision of data about police shootings, and note that we know almost nothing about non-fatal shootings. They observe that injury prevention programs based in hospitals have the capacity to improve data quality on non-fatal shootings by the police. They interviewed doctors, nurses, and others to find out if this idea might have salience. On balance, they find that this would be feasible as a method for collecting these missing data.

Like Sewell and Jefferson, Rengifo and Fowler posit that police stops may be highly varied, and that different types of stops may have different consequences. Using NYPD stop and frisk data, they characterize stops in terms of rationale (vague vs specific), setting (e.g., public housing complex, transit system) and intrusiveness, and aggregate data to NYC's police precincts. Their longitudinal ecologic analysis suggests that precincts with higher rates of stops formally attributed to a vague rationale (e.g., for a suspicious bulge), of intrusive stops, and of stops in the transit system had higher rates of complaints filed with the NYC Civilian Complaint Review Board; notably, rates of stops by uniformed officers were inversely associated with complaint rates. Combined with Sewell and Jefferson's work, these findings testify to the importance of moving beyond measures that simply capture the total number (or rate) of stops to create measures that seek to quantify specific characteristics of stops, and explore the distinct ramifications of these characteristics for the public's health.

Gilbert and Ray's theoretical paper uses "public health critical race theory" to examine existing data about the process and outcomes of police brutality. They note, "We aimed to integrate all principles that span each of [several] focal areas: (a) race consciousness, (b) the primacy of racialization, (c) race as a social construct, (d) gender as a social construct (author's addition to the original model), (e) ordinariness of racism, (f) structural determinism, (g) social construction of knowledge, (h) critical approaches, (i) intersectionality, (j) inter-disciplinary 
selfcritique, and ( $\mathrm{k}$ ) voice." The authors use this analysis to arrive at a set of recommendations for a multi-level intervention into the problem.

\section{FUTURE DIRECTIONS FOR RESEARCH}

These papers, by tackling an array of domains, suggest the problem we face is both tenacious and multi-faceted. It is typically impossible to solve such problems without a socio-ecological framework and coordinated action. Police culture, police unions, violence as a tool of social stratification, poverty, perceived rates of crime, policies of mass incarceration, and absence of police oversight-to name some of the factors-operate together to create the current levels of excessive police violence. Interventions that target only one or few of these aspects of the situation will fall short. A useful example is found in the control of schistosomiasis, a parasitic infection that is second to malaria in its health consequences. The parasite has a complex life cycle, which includes snails, fresh water, and humans, at a minimum. While drugs have great utility, experience has shown that a combination of killing snails, protecting the fresh water supply and using medication is essential for sound control of this terrible infection. ${ }^{10} \mathrm{~A}$ similarly complex understanding of the life cycle of police violence will be of great utility as we move forward.

Some specific areas of research will help to build this comprehensive conceptual model:

I. Conceptualization: We can mine past public health work on violence to help refine our understanding of excessive police violence. To date, public discourse has focused overwhelmingly on extreme physical violence (i.e., death), but the World Health Organization (WHO) identifies four types of violence: psychological violence, physical violence, sexual violence, and neglectful violence. ${ }^{11}$ These categories can be mapped onto excessive police violence. $^{7}$ A key next step for research is to systematically determine whether the prevalence and health consequences of each type varies across subpopulations.

WHO defines collective violence as “...the instrumental use of violence by people who identify themselves as members of a group...against another group or set of individuals, in order to achieve political, economic or social objectives." $\left({ }^{11}\right.$, page 215) This construct and related literature could support analyses of the health and health equity impacts of excessive police violence, conceptualized as a potent tool for maintaining White supremacy and other forms of oppression.

II. Measurement: It is difficult to quantify the public health consequences of excessive police violence if we cannot measure it. Several papers in this special issue grapple with this topic, as have Krieger and colleagues. ${ }^{12}$ There are no valid surveillance data on fatal or non-fatal injuries at the hands of the police in the USA. The release of "stop and frisk" data in several jurisdictions has been a boon to research on excessive police violence and its health consequences, though recent evidence suggests that officers are now submitting incomplete data to obscure key dimensions of these stops. ${ }^{13}$ Creating a federal monitoring system of fatal and non-fatal injuries by police is a vital first step in assessing the prevalence and health impacts of excessive police violence; reporting must be mandatory for all jurisdictions and include information on the victim's social position. We note, however, that this system would be limited. It would not capture neglectful violence, and would 
likely dramatically undercount instances of psychological and sexual violence. Moreover, it would likely not be a source of data on excessive police violence. Police officers are empowered to use force, provided that they use the minimal amount needed to "control an incident, effect an arrest, or protect themselves or others from harm or death."14 The line between necessary and excessive force is hotly contested, and has historically been decided overwhelmingly in favor of officers.

To complement surveillance data, we must develop and validate survey-based measures of self-reported exposure to excessive police violence. Measures should, at a minimum, recognize that this violence can be physical, sexual, psychological, and neglectful, and can be directly experienced or witnessed (i.e., community violence).

III. Analyses: Policing is inherently spatial, and law enforcement strategies associated with excessive police violence are more likely to be deployed in predominately impoverished Black and Latino neighborhoods than elsewhere; within (and outside of) these neighborhoods, there is considerable variation in direct experiences of excessive police violence by gender, social class, perceived or actual criminal involvement, and other characteristics. ${ }^{5-8}$ Studies seeking to quantify the public health effects of excessive police violence must recognize the resulting differential prevalence of exposure across racial/ethnic groups and other subpopulations. Odds ratios and other kinds of effect estimates merely quantify the extent to which the outcome varies as the exposure varies; they fail to incorporate differential exposure across subpopulations. ${ }^{15,16}$ Population attributable risk percents, however, incorporate both the prevalence of the exposure and the effect estimate, ${ }^{16}$ and can thus be a powerful tool for quantifying the true public health effects of excessive police violence, particularly when calculated for specific racial/ ethnic groups and for subsets within those groups defined by gender, social class, perceived or actual criminal involvement, sexual orientation, and other dimensions of social position. Population attributable risk percents have assumptions which this line of inquiry may not yet meet, including assuming that a causal relationship exists between the exposure and the outcome. The extent to which these assumptions are met can be thoughtfully discussed and should not preclude efforts to calculate population attributable risk percents.

IV. Interventions: Several municipal governments and police departments have created initiatives to reduce excessive police violence and its adverse effects (e.g., ${ }^{13,17}$ ). Health impact assessments should compare and contrast the effects of different initiatives on health, with particular attention to decays over time in improvements and to differential effects across subpopulations.

V. Public health leadership: Excessive police violence is centuries old-it predates the creation of the USA ${ }^{18,19}$ - and yet there was virtually no research on its public health impacts until recently. One primary reason for this, we propose, is that leaders within the field of public health have been predominately non-Hispanic White, and thus did not live in communities that were targeted by excessive police violence, and benefited, whether willingly or not, from the system of White supremacy that excessive police violence supports. Ensuring that the sociodemographic compositions of public health professionals at all ranks reflect those of the populations served is vital if we are to engage with the full range of determinants of population health and disease. 


\section{CONCLUSION}

This special issue of the Journal of Urban Health creates a vital foundation for answers to the question, "How can we stop this racially biased epidemic of excessive police violence?" The papers provide insights into ways to constructively engage public health theories, methods, and interventions to study this epidemic. But the work presented here leaves more questions than it answers. A concerted public health push to eliminate excessive police violence is badly needed. This is not only a question of excess mortality but also a question of taking a stand for a law-abiding democracy in which all can prosper. We can point to all too many epidemics "redlined" because they "affected" people of color, ignoring the deeper truth of the interrelated web of existence. Let us move forward, charting a public health that really fights for the health of the whole public.

\section{ACKNOWLEDGMENTS}

We want to thank the authors who contributed to this special issue for their excellent and thought-provoking work, and the reviewers for their insightful comments about the manuscripts. This work was supported by "Place Characteristics \& Disparities in HIV in IDUS: A Multilevel Analysis of NHBS" (DA035101; Cooper, PI) and the Emory Center for AIDS Research (P30 AI050409; Curran, PI).

\section{REFERENCES}

1. Dahlberg L, Mercy J. History of violence as a public health issue. AMA J Ethics. 2009; 11(2): 167-172.

2. Centers for Disease Control and Prevention. Health objectives for the nation. MMWR. 1989; 38(37): 629-633.

3. Berkman LF, Kawachi I. Social epidemiology. New York, NY: Oxford University Press; 2000.

4. Kawachi I, Berkman L. Neighborhoods and health. New York, NY: Oxford University Press; 2003.

5. Maher L, Dixon D. Policing and public health: law enforcement and harm reduction in a street-level drug market. Br J Criminol. 1999; 39(4): 488-512.

6. Rhodes T, Wagner KD, Strathdee SA, Shannon K, Davidson P, Bourgois P. Structural violence and structural vulnerability within the risk environment: theoretical and methodological perspectives for a social epidemiology of HIV risk among injection drug users and sex workers. In: O'Campo P, Dunn JR, eds. Rethinking social epidemiology: toward a science of change. New York, NY: Springer; 2012: 205-230.

7. Cooper H, Moore L, Gruskin S, Krieger N. Characterizing perceived police violence: implications for public health. Am J Public Health. 2004; 94(7): 1109-1118.

8. Cooper H, Moore L, Gruskin S, Krieger N. The impact of a police drug crackdown on drug injectors' ability to practice harm reduction: a qualitative study. Soc Sci Med. 2005; 61(3): 673-684.

9. Markwick N, McNeil R, Small W, Kerr T. Exploring the public health impacts of private security guards on people who use drugs: a qualitative study. J Urban Health. 2015; 92(6): 1117-1130.

10. Utzinger J, N'Goran E, Caffrey C, Keiser J. From innovation to application: socialecological context, diagnostics, drugs and integrated control of schistosomiasis. Acta Trop. 2011; 120: S121-S137.

11. Krug E, Dahlberg L, Mercy J, Zwi A, Lozano R. World report on violence and health. Geneva, Switzerland: WHO; 2002. 
12. Krieger N, Chen J, Waterman P, Kiang M, Feldman J. Police killings and police deaths are public health data and can be counted. PLoS Med. 2015; 12(12): e1001915.

13. Baker A. New York police still struggle to follow street-stop rules, report finds. New York Times. 2016. http://www.nytimes.com/2016/02/17/nyregion/new-york-police-struggle-tofollow-new-street-stop-policy-report-finds.html?_r=0. Accessed 2 Mar 2016.

14. The National Institute of Justice. Police use of force. 2012. Retrieved January 82015 from http://www.nij.gov/topics/law-enforcement/officer-safety/use-of-force/pages/ welcome.aspx.

15. Hennekens $\mathrm{CH}$, Buring JE. Epidemiology in medicine. Boston, MA: Little, Brown and Company; 1987.

16. Northridge ME. Annotation: public health methods-attributable risk as a link between causality and public health action. Am J Public Health. 1995; 85(9): 1205-1206.

17. Broadwater L, Puente M. Baltimore officials offer plan to curb police brutality. The Baltimore Sun. 2014. Retrieved March 22016 from http://www.baltimoresun.com/news/ maryland/sun-investigates/bs-md-police-report-20141007-story.html.

18. Bass S. Policing space, policing race: social control imperatives and police discretionary decisions. Soc Justice. 2001; 28(1): 156-176.

19. Cooper HL. War on drugs policing and police brutality. Subst Use Misuse. 2015; 50(8-9): 1188-1194. 